\title{
Elaboração de um livro infantil para conversar sobre Anemia Falciforme
}

\author{
Preparation of a children's book to talk about Sickle Cell Disease \\ Preparación de un libro infantil para hablar de la Anemia de Células Falciformes
}

Recebido: 27/01/2022 | Revisado: 31/01/2022 |Aceito: 03/02/2022 | Publicado: 05/02/2022

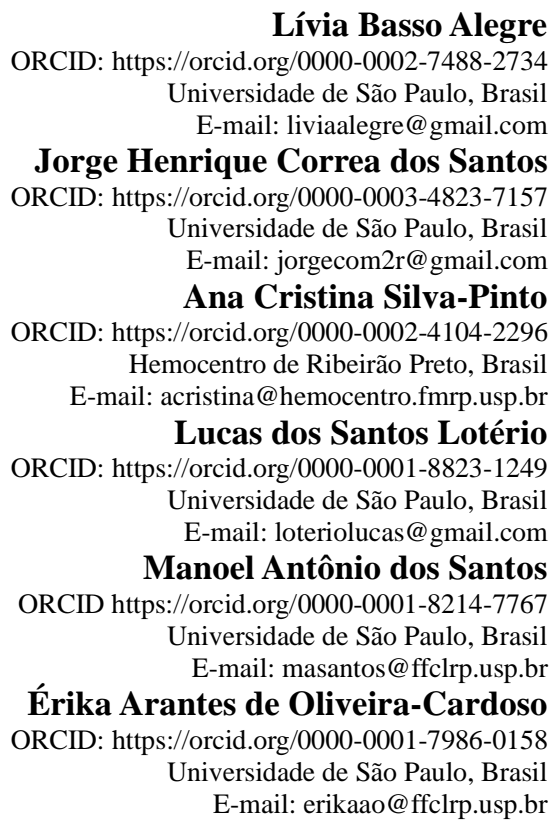

\section{Resumo}

Anemia Falciforme (AF) é uma doença hematológica, genética e crônica, que muitas vezes requer hospitalizações e exige atendimento ambulatorial constante. O objetivo deste estudo é descrever as etapas de elaboração de um livro com o propósito de encorajar conversas com crianças com AF sobre a doença, explicando seu funcionamento, sintomatologia e limitações acarretadas no cotidiano. Foram seguidas as seguintes etapas: a) elaboração do projeto, b) seleção de conteúdos, por meio de revisão da literatura sobre sintomatologia e limitações decorrentes da AF; c) elaboração da história: escolha da escola como cenário e da personagem Amanda, uma menina preta, como protagonista do livro; d) elaboração do livro piloto; e) revisão e validação por especialistas: o material foi analisado por psicólogos e médicos com experiência no assunto e crianças sem diagnóstico clínico; f) adequação da linguagem e conteúdos: foram realizadas as adaptações sugeridas; g) nova submissão do material aos especialistas; h) finalização do livro: o material foi ilustrado, catalogado e impresso. Os principais tópicos abordados na história foram: necessidade de eventuais faltas na escola, restrições de atividades físicas escolares, definições da doença, crise, sintomas e tratamento. $\mathrm{O}$ enredo encerra com a possibilidade de inserir o paciente com AF em uma rotina adaptada na escola e com dicas para pais e professores. O material produzido poderá ser utilizado em diversos contextos, como na saúde e na escola. Além do caráter educativo, o livro poderá ser usado como material intermediário facilitador para a expressão afetiva das crianças com AF que se identificaram com a vivência da personagem Amanda. (Apoio: Programa Unificado de Bolsas da Universidade de São Paulo - PUB-USP).

Palavras-chave: Anemia Falciforme; Livros ilustrados; Materiais de ensino; Cuidado da criança; Educação em saúde.

\begin{abstract}
Sickle Cell Anemia (SCA) is a hematological, genetic, and chronic disease that often requires hospitalizations and constant outpatient care. This study aims to describe the steps in the elaboration of a book with the purpose of encouraging conversations with children with AF about the disease, explaining its functioning, symptomatology, and limitations it entails in daily life. The following steps were followed: a) preparation of the project, b) selection of content, through a literature review on symptoms and limitations arising from SCA; c) development of the story: choice of the school as the setting and of the character Amanda, a black girl, as the protagonist of the book; d) development of the pilot book; e) review and validation by experts: the material was analyzed by psychologists and doctors with experience in the subject and children without clinical diagnosis; f) adequacy of language and contents: the suggested adaptations were made; g) new submission of the material to the experts; h) finalization of the book: the
\end{abstract}


material was illustrated, cataloged and printed. The main topics addressed in the story were: the need for eventual school absences, school physical activity restrictions, definitions of the disease, crisis, symptoms, and treatment. The storyline ends with the possibility of inserting the patient with SCA in an adapted routine at school and with tips for parents and teachers. The material produced can be used in various contexts, such as health care and school. Besides the educational character, the book can be used as an intermediary material facilitator for the affective expression of children with SCA who identify themselves with the experience of the character Amanda. (Support: Programa Unificado de Bolsas da Universidade de São Paulo - PUB-USP).

Keywords: Sickle Cell Anemia; Books, illustrated; Teaching materials; Child care; Health education.

\section{Resumen}

La Anemia de Células Falciformes (ACS) es una enfermedad hematológica, genética y crónica que suele requerir hospitalizaciones y exige una atención ambulatoria constante. Este estúdio tiene por objetivo describir los pasos en la elaboración de un libro con el fin de fomentar las conversaciones con niños con ACS sobre la enfermedad, explicando su funcionamiento, los síntomas y las limitaciones que conlleva en la vida cotidiana. Se siguieron los siguientes pasos: a) elaboración del proyecto, b) selección de contenidos, a través de una revisión de la literatura sobre los síntomas y las limitaciones derivadas de la ACS; c) elaboración de la historia: elección de la escuela como escenario y del personaje Amanda, una niña negra, como protagonista del libro; d) elaboración del libro piloto; e) revisión y validación por parte de especialistas: el material fue analizado por psicólogos y médicos con experiencia en el tema y niños sin diagnóstico clínico; f) adecuación del lenguaje y de los contenidos: se realizaron las adaptaciones sugeridas; g) nueva presentación del material a los expertos; h) finalización del libro: el material fue ilustrado, catalogado e impreso. Los principales temas abordados en el relato fueron: la necesidad de eventuales ausencias escolares, las restricciones de las actividades físicas en la escuela, las definiciones de la enfermedad, la crisis, los síntomas y el tratamiento. La historia se cierra con la posibilidad de insertar al paciente con ACS en una rutina adaptada en la escuela y con consejos para padres y profesores. El material producido puede utilizarse en diversos contextos, como la salud y la escuela. Además de su carácter educativo, el libro puede utilizarse como material intermedio para facilitar la expresión afectiva de los niños con ACS que se identifican con la experiencia del personaje Amanda. (Apoyo: Programa Unificado de Bolsas da Universidade de São Paulo - PUB-USP).

Palabras clave: Anemia de Células Falciformes; Libros ilustrados; Materiales de ensenãnza; Cuidado del niño; Educación en salud.

\section{Introdução}

A Anemia Falciforme (AF) é uma doença genética autossômica recessiva, caracterizada como uma anemia hemolítica que tem como fator etiológico uma mutação que afeta a formação da hemoglobina S. Os glóbulos vermelhos se apresentam em forma de foice, resultando em hemólise acelerada e maior propensão à ocorrência de obstrução dos vasos sanguíneos (Zago \& Pinto, 2007). Trata-se da doença genética hereditária dos glóbulos vermelhos mais comum no mundo e acomete, principalmente, descendentes de povos africanos, mediterrâneos e asiáticos. Estima-se que nasçam, por ano, cerca de 200.000 crianças com AF, principalmente na África subsaariana. Nos Estados Unidos aproximadamente 2.000 crianças nascem com a doença todos os anos, com uma incidência estimada em 1 a cada 2.474 nascidos vivos (Kanter \& Kruse-Jarres, 2013). No Brasil estima-se o nascimento de cerca de 3.000 crianças com Doença Falciforme anualmente, o que corresponde a uma taxa de um para cada 1.000 recém-nascidos vivos (Cançado et al., 2009).

Caracterizada por elevada morbidade e mortalidade, as manifestações clínicas da AF são agudas e podem aparecer já nos primeiros meses de vida. Algumas das expressões da doença são: crises vaso-oclusivas dolorosas, sequestro esplênico, síndrome torácica aguda e processos infecciosos graves. Durante a infância, há possibilidades críticas de ocorrência de acidente vascular cerebral (AVC), e durante a adolescência e início da vida adulta há maior probabilidade de ocorrência de úlcera nas pernas (Felix et al., 2010).

O Transplante de Células-Tronco Hematopoéticas (TCTH) é o único método curativo conhecido para pacientes com AF. É oferecido quase que de forma exclusiva a pessoas com doador familiar compatível, sendo, frequentemente, um irmão (Lotério et al., 2022; Saraf et al., 2018). Apenas 38\% das pessoas com AF apresentam os pré-requisitos para o transplante (Hoppe \& Walters, 2001), portanto, a qualidade de vida dos pacientes depende do diagnóstico neonatal, da penicilina 
profilática, dos cuidados familiares e da dedicação do próprio indivíduo, com amparo da educação em saúde e acesso a informação qualificada sobre a doença.

O paciente com AF necessita adaptar-se a hábitos de vida que se diferenciam da população geral, principalmente devido ao uso continuado de medicamentos e das constantes internações hospitalares, sendo que crianças e adolescentes que têm hemoglobinopatia necessitam reduzir as horas dispensadas à escola e às atividades produtivas (Ezenwosu et al., 2021). Além da necessidade de afastamentos escolares recorrentes, que podem impactar no desenvolvimento cognitivo e em dificuldades de aprendizagem, os pacientes necessitam lidar com a dor crônica, sendo essa a principal causa de internação das crianças acometidas (Freire et al., 2020). Essa vicissitude pode favorecer com que os níveis de estresse, ansiedade e depressão em crianças sejam mais elevados do que na população geral. Os riscos enfrentados pelas crianças com dor crônica podem se estender à fase adulta, acarretando dores mais intensas e aumentando a suscetibilidade a problemas psicológicos (Palermo et al., 2011).

Nesse cenário, torna-se imperativo desenvolver recursos que facilitem a adaptação às mudanças exigidas no estilo de vida e também um esforço redobrado de compreensão, aceitação e cooperação com o tratamento. O paciente com AF, desde os estágios iniciais do desenvolvimento, é desafiado a aprender a conviver com suas limitações, e a despeito de as crianças apresentarem certa maturidade precoce, ter de lidar com a sintomatologia e com sua autoimagem prejudicada pode desencadear sentimentos negativos, tais como medo, vergonha, raiva e tristeza (Nóbrega et al., 2010).

Em vista disso, conhecer sua própria doença se torna fundamental, uma vez que estimula o autoconhecimento e contribui para o desenvolvimento da autonomia pessoal, fortalecendo a autoestima e a adesão ao tratamento e a um estilo de vida saudável. A educação em saúde deve assegurar maior liberdade para a criança opinar sobre os rumos a serem seguidos, compartilhando as decisões sobre o tratamento com a família e a equipe médica (Tates \& Meeuweesen, 2001). Desse modo, esclarecer o paciente o mais amplamente possível sobre sua doença e tratamento aumenta seu senso de controle sobre as situações que atravessam sua existência e, consequentemente, pode incrementar sua colaboração com os profissionais de saúde, diminuindo sua sensação de passividade e favorecendo melhor ajustamento psicossocial à enfermidade.

No cenário do tratamento é notória a escassez de materiais e instrumentos que possam facilitar a comunicação entre pacientes e profissionais. Na perspectiva da promoção de saúde, há necessidade de desenvolver recursos que potencializem o diálogo sobre as questões relacionadas à doença e seu tratamento, que possam ajudar as crianças que convivem com as limitações cotidianas a compreenderem o que está acontecendo no seu corpo e como o tratamento age em seu organismo. Manuais de divulgação e cartilhas educativas podem auxiliar o trabalho da equipe nas orientações relacionadas aos cuidados de saúde, contribuindo para que o paciente compreenda sua doença e mantenha sua motivação elevada para colaborar com a equipe (Nascimento et al., 2020). Esses materiais são recursos de apoio que se enquadram entre as diversas Tecnologias Educacionais em Saúde, que podem ser compreendidas como meios de intermediação do processo ensino-aprendizagem e que podem assumir diversas apresentações - no presente estudo, a forma impressa, de livro ilustrado (Nascimento et al., 2020).

Segundo Echer (2005), no processo de elaboração desse tipo de material, que tem como propósito funcionar como mediador dialógico, é necessário resguardar o rigor metodológico. Para tanto, uma sequência de passos é sugerida: 1) elaboração do projeto; 2) estudo da literatura da área; 3) tornar acessível a linguagem científica e selecionar informações relevantes; 4) qualificação do material, que implica a avaliação do livro/manual produzido, o que pode ser feito por profissionais e/ou pacientes. Além disso, a cartilha (ou manual) deve ser construída a partir dos conhecimentos das diferentes áreas da saúde sobre o tema, com a preocupação de que a linguagem utilizada seja acessível e apropriada ao nível de compreensão de diversos públicos (Enumo et al., 2022). 
Considerando o exposto, o objetivo deste estudo é descrever as etapas de elaboração de um livro com o propósito de encorajar conversas com crianças com AF sobre a doença, explicando seu funcionamento, sintomatologia e limitações acarretadas.

\section{Metodologia}

Trata-se de uma Pesquisa Convergente Assistencial (PCA), um tipo de delineamento que busca estabelecer uma relação direta entre métodos de pesquisa e a prática assistencial. Este desenho de pesquisa visa, dentre outros objetivos: a) introduzir inovações, ou minimizar problemas, na área da investigação; b) responder questões que emergem na prática dos profissionais e usuários de serviços de saúde; c) manter o compromisso com a construção de um novo conhecimento que contribuirá para o aprimoramento das práticas assistenciais; d) valorizar o uso de diferentes métodos de investigação para coleta e análise dos dados (Rocha et al., 2012). Essa abordagem metodológica tem sido utilizada para a construção de materiais educativos no cenário da educação em saúde (Silva et al., 2020).

Para a elaboração do livro infantil sobre AF foram seguidas as etapas sugeridas por Echer (2005) (Quadro 1).

Quadro 1. Etapas da elaboração do livro infantil sobre AF.

\begin{tabular}{ll}
\hline \multicolumn{1}{c}{ Etapas } & \multicolumn{1}{c}{ Descrição } \\
\hline $\begin{array}{l}\text { Elaboração do } \\
\text { projeto }\end{array}$ & $\begin{array}{l}\text { Realização de uma revisão sistematizada da literatura sobre sintomatologia e } \\
\text { limitações acarretadas pela AF no cotidiano da criança. }\end{array}$ \\
\hline $\begin{array}{l}\text { Seleção do conteúdo e } \\
\text { elaboração da } \\
\text { história }\end{array}$ & $\begin{array}{l}\text { Identificação dos sintomas mais frequentes e das possibilidades de intervenção; } \\
\text { Escolha da escola como cenário da história; } \\
\text { Definição dos personagens da história; escolha de Amanda, uma menina preta, como } \\
\text { protagonista do livro e de Gabriel, um menino asiático, como personagens do livro; } \\
\text { Opção pelo formato de diálogos entre os personagens como estratégia facilitadora da } \\
\text { comunicação entre autores e leitores do material produzido. }\end{array}$ \\
\hline $\begin{array}{l}\text { Elaboração do livro } \\
\text { piloto }\end{array}$ & $\begin{array}{l}\text { A primeira versão do livro foi desenvolvida sem as ilustrações gráficas, contendo } \\
\text { somente o texto e os diálogos do enredo. }\end{array}$ \\
\hline $\begin{array}{l}\text { Revisão e validação } \\
\text { de conteúdo por } \\
\text { especialistas }\end{array}$ & O material foi analisado por médicos e psicólogos com experiência no tema. \\
\hline $\begin{array}{l}\text { Adequação da } \\
\text { linguagem e conteúdo }\end{array}$ & $\begin{array}{l}\text { Após incorporar as adaptações sugeridas pelo comitê de especialistas, o material foi } \\
\text { submetido novamente aos profissionais para confirmação da adequação das } \\
\text { reformulações realizadas no conteúdo. }\end{array}$ \\
\hline $\begin{array}{l}\text { Avaliação e validação } \\
\text { de conteúdo por } \\
\text { crianças }\end{array}$ & $\begin{array}{l}\text { O material com a versão final foi lido para crianças de diferentes faixas etárias para } \\
\text { investigar a adequação e compreensão da linguagem. }\end{array}$ \\
\hline Finalização do livro & $\begin{array}{l}\text { O material foi ilustrado e enviado para catalogação pela Câmara Brasileira do Livro, } \\
\text { sendo posteriormente diagramado, impresso e distribuído gratuitamente em } \\
\text { Hemocentros de todo o país. }\end{array}$ \\
\hline
\end{tabular}

Fonte: Autores.

O primeiro passo foi a redação do projeto, com base em uma revisão da literatura que proporcionou uma compreensão mais abrangente sobre a doença, sua etiopatologia, sintomatologia e limitações acarretadas no cotidiano dos pacientes, de maneira que a história pudesse ser o mais representativa possível dos reais problemas enfrentados para o ajustamento às restrições vivenciadas, levando os leitores a se identificarem com o material. Concluída esta etapa da pesquisa, iniciou-se o processo de composição da história a partir das informações coletadas. Isso demandou filtrar as informações mais significativas sobre o funcionamento da $\mathrm{AF}$ e identificar aquelas que seriam incluídas na história. Constatou-se que as manifestações mais comuns em pacientes falciformes são as crises vaso-oclusivas e as crises dolorosas. Por essa razão, estes sintomas foram priorizados e incluídos como principais manifestações da doença (Freire et al., 2020). 
Em seguida, foi concebida a personagem Amanda, uma menina preta, definida como protagonista do livro. Essa escolha ocorreu devido a maior prevalência da AF na população negra. Dessa maneira, foi possível resguardar certa representatividade dentro da história. Como cenário principal foi definida a escola, considerando que um espaço de sociabilidade determinante para o desenvolvimento cognitivo e social infantil e que é o contexto no qual é construída grande parte da identidade da criança e seu sentimento de ser e pertencer ao mundo.

Além disso, o ambiente escolar é impactado pelo adoecimento, principalmente quando se tratam de doenças crônicas, já que as crianças que vivenciam essa condição de vulnerabilidade têm mais probabilidade de enfrentarem dificuldades de integração e socialização (Brito et al., 2017). Além disso, é importante que os educadores compreendam as barreiras e limitações que a AF impõe às crianças, para que possam se instrumentalizar para prover uma assistência mais adequada e sensível a suas necessidades específicas (Custódio et al., 2018.)

A primeira autora escreveu a versão inicial da história, que foi submetida a um processo de revisão e validação por uma equipe de especialistas formada por médicos e psicólogos com experiência na área e por crianças da faixa etária para qual o livro foi planejado. Primeiramente, os profissionais deram sugestões para adequar os conteúdos, ajustando a linguagem para que o livro pudesse ser compreendido pelo público de forma clara e acessível para todas as camadas sociais e, ao mesmo tempo, veiculasse informações apropriadas do ponto de vista técnico-científico.

Concluídas as adaptações necessárias, o material foi submetido novamente aos profissionais para confirmação da adequação dos ajustes realizados no conteúdo. Após essa última conferência, o texto foi considerado satisfatório e o material resultante foi lido para seis crianças (sem diagnóstico clínico), sendo três meninas $(6,9$ e 10 anos) e três meninos (7, 8 e 11 anos), com a finalidade de investigar a compreensão do texto. Na avaliação das crianças, o livro é de fácil compreensão, mesmo sem mediação de adultos, para a faixa etária de 6 a 11 anos.

Uma vez concluída a etapa de adaptação do conteúdo, o livro foi ilustrado. Nessa etapa, o personagem Gabriel foi idealizado como um garoto asiático, para reforçar a diversidade. Ademais, optou-se por uma ilustração colorida e mais simplificada, não elaborada por um ilustrador profissional, privilegiando o aspecto artesanal para dar destaque à expressão dos sentimentos dos personagens.

Em seguida, o livro foi finalizado e submetido à catalogação pela Câmara Brasileira do Livro (CBL), onde recebeu um registro de ISBN (International Standard Book Number) e uma ficha catalográfica. Por fim, o material foi impresso e lançado pela Editora Espaço Psi. Depois de pronto, exemplares foram enviados para profissionais de outros centros especializados e para mães de pacientes com AF, que deram um feedback positivo em relação à qualidade do material, conteúdos selecionados e clareza das informações fornecidas.

\section{Resultados}

O livro conta a história de Amanda, uma menina com $\mathrm{AF}$ que, por ter tido uma crise de dor recentemente, não pode participar da aula de Educação Física. Ao ver sua amiga sentada na arquibancada da quadra, e curioso para saber o que aconteceu com ela, seu colega de turma, Gabriel, se aproxima para perguntar à amiga o motivo de ela não estar na aula (Figura $1)$. 
Figura 1. Contexto no qual se desenvolve a história.

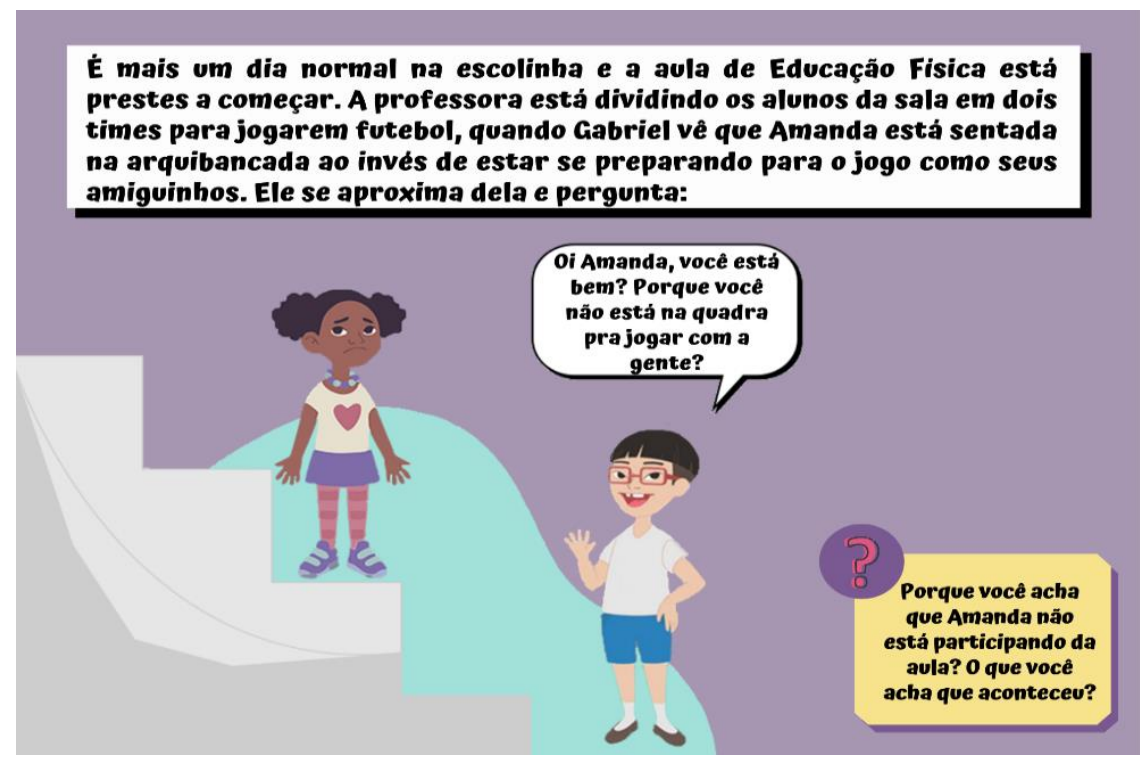

Fonte: Autores.

A partir desse diálogo suscitado pela curiosidade de Gabriel, Amanda conta a Gabriel sobre sua doença, seus sintomas, seu tratamento e sua experiência de conviver com a AF. O enredo do livro se desenvolve de maneira interativa com a criança-leitora, estimulando-a a expressar aquilo que ela já conhece ou pensa sobre o tema, para que se possa ampliar e/ou corrigir seus conhecimentos, quando necessário (Figura 2).

Figura 2. Exemplos de questões para animar a conversa com as crianças.

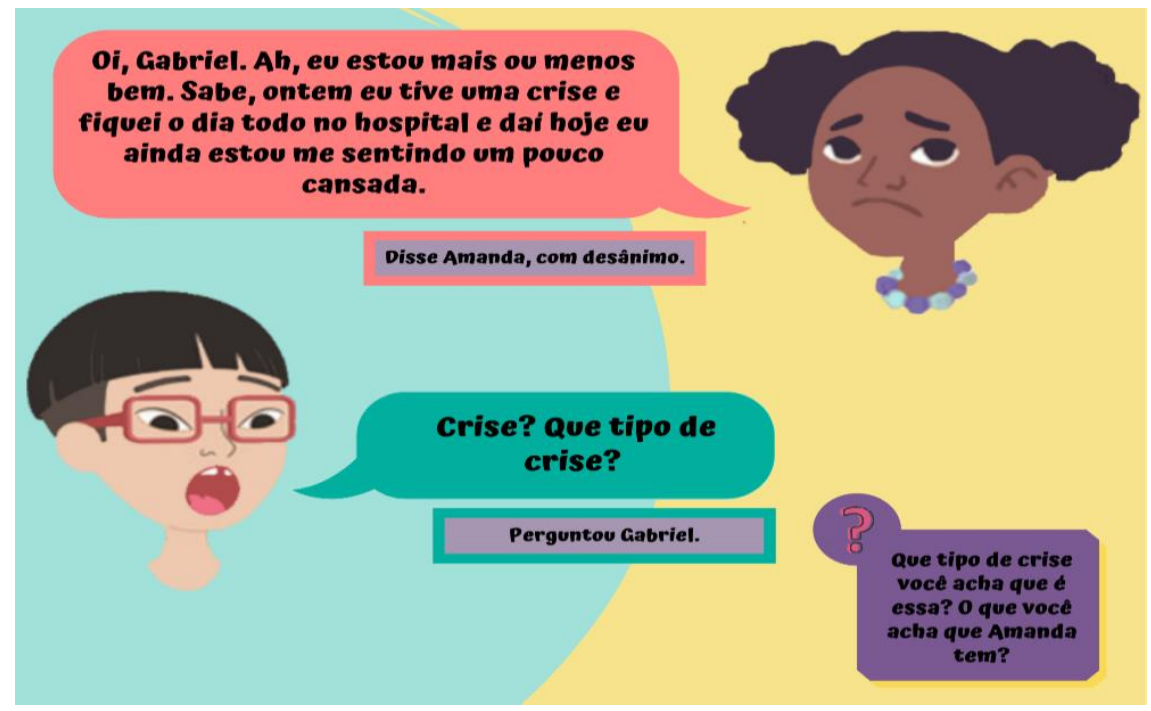

Fonte: Autores.

Antes de iniciar a conversa sobre a $\mathrm{AF}$, as perguntas direcionadas à criança são mais gerais, para que ela possa imaginar aquilo que aconteceu com a personagem Amanda e ofereça uma resposta a partir de suas conjecturas. Depois, ainda nessa seção do livro, foram utilizadas as questões: "Por que você acha que Amanda não está participando da aula?" e "O que você acha que aconteceu?". Após esse aquecimento inicial é abordado o funcionamento da AF, quando são feitas perguntas para o leitor: “O que é AF?", "Você sabe em qual parte do corpo que fica?", "Como você acha que é a doença?”. Depois dessa 
exploração de conceitos mais gerais, são mencionadas as crises de dor por meio da questão: "Como você acha que são essas crises? O que você acha que acontece?". Por fim, são introduzidas as formas de tratamento da doença por meio das perguntas: "Essa doença tem cura?" e "Você sabe o que deve ser feito?", que se referem aos cuidados que devem ser tomados pelos pacientes com AF.

Ao final do livro foram inseridas as "dicas da Amanda" direcionadas para os cuidadores e professores da criança. Essas dicas foram divididas em duas categorias: "Dicas da Amanda para pais ou responsáveis" e "E durante a aula de educação física?". A primeira aborda cuidados mais gerais com a criança e sugestões para uma inserção na rotina escolar. Foram disponibilizadas, nessa parte, informações sobre a importância da comunicação entre os cuidadores e a escola, como por exemplo: "Informe ao professor da criança sobre a doença e quais são as suas possíveis complicações" e "Crianças com Anemia Falciforme produzem mais urina, por isso devem ter permissão para deixarem a sala e irem ao banheiro quando necessitarem", além de indicações de cuidados para o dia a dia tais como: "É importante agasalhar bem a criança durante o período de frio e usar roupas leves durante o verão. E sempre usar sapatos e meias para evitar machucados nas pernas" e "Uma boa alimentação é fundamental. As crianças devem se alimentar com legumes, verduras, frutas e carne".

Na categoria "E durante a aula de educação física?" foram adicionadas dicas especialmente para essa atividade, já que, com a autorização do médico hematologista, a criança pode e deve ser incentivada a praticar exercícios físicos. Nessa seção foram inseridas indicações tais como: "Pratique as atividades de forma moderada, alternando turnos entre descanso e exercício", "A criança deve ingerir bastante líquido durante a aula" e "Parar a qualquer momento de se exercitar, caso sinta falta de ar ou dores". Adicionalmente, também foram inseridas, no final do livro, as "Informações da Amanda para pais ou responsáveis", contendo uma explicação mais detalhada da doença. Essa parte foi pensada para contemplar tanto os cuidadores quanto pacientes mais velhos que possam eventualmente ter contato com o material. O livro foi distribuído, gratuitamente, para equipes, pacientes e familiares de hemocentros do país.

\section{Repercussões do material junto ao público infantil e aos pacientes adultos, familiares e equipe de saúde}

Foi solicitada às crianças, aos pacientes, familiares e profissionais que trabalham com AF uma apreciação geral do livro. Crianças que não têm a doença avaliaram positivamente o material, confirmando que conseguiram compreender o texto:

Não tinha nenhuma palavra que eu não entendi... Eu não conhecia essa doença e fiquei com pena da Amanda... que bom que o Gabriel é amigo dela e conseguiu ajudar (Masculino, 10 anos).

Eu entendi quase tudo desse livro. Anemia Falciforme está no sangue, é uma doença que não tem cura [...] a pessoa com anemia falciforme precisa ir ao hospital para fazer um tratamento, mas ela pode fazer tudo, tudinho na vida (Feminino, 6 anos).

Pacientes adultos que tiveram contato com o material também manifestaram suas impressões:

Você não sabe como esse livro me deixou feliz. Tenho Anemia Falciforme e é incrível ver que ela está sendo discutida. Ai como eu queria ser criança para apresentar esse livro para os meus coleguinhas (Feminino, AF).

Fico tão feliz de ver profissionais falando sobre a Doença Falciforme... ainda mais dessa forma (Feminino, AF).

A devolutiva de familiares seguiu a mesma tônica de aprovação e reconhecimento da relevância e da necessidade de elaborar esse tipo de material informativo:

Eu preciso aprender a lidar com meu próprio filho em relação à doença, e tudo o que puder me ajudar eu peço pra médica e para as enfermeiras, e foi onde me indicaram esse livro. Deus abençoado, vai ser muito bom, tanto pra ele 
como pra mim, eu também vou compartilhar com as outras mães daqui, e vai ser de grande ajuda (Mãe de menino de três anos com AF, Rondônia).

O depoimento dessa mãe mostra que o material está alcançando outros estados, inclusive de regiões distantes dos centros economicamente mais desenvolvidos do país, e que já começa a ser reconhecido e recomendado por profissionais da área. Psicólogos e enfermeiros vinculados a um serviço de saúde de Curitiba, Paraná, enviaram os seguintes comentários:

Li e achei uma fofura. Mais do que isso, muito esclarecedor (Enfermeira, Hemocentro de Curitiba)

O livro ficou muito bom. E o título ficou perfeito porque desperta curiosidade. "Uma aula diferente”, hum! O que será isso? Entende? Acho que chama a atenção. E vocês também mostram a compaixão, o companheirismo do amiguinho que fica jogando xadrez com ela. No final tem uma síntese que centraliza as informações para os pais, achei bem importante isso (Psicóloga, Hospital das Clínicas de Curitiba).

Além da receptividade do público-alvo, a comunidade científica da área também reconheceu a relevância e pioneirismo desta iniciativa, com sua consagração como o melhor trabalho da equipe multidisciplinar (Prêmio Fany Job) no Congresso da Sociedade Brasileira de Transplante de Medula Óssea - SBTMO, realizado em 2020. O estudo também ganhou menção honrosa no $19^{\circ}$ Simpósio Internacional de Iniciação Científica da Universidade de São Paulo - SIICUSP, realizado em 2021.

A leitura do livro e avaliação do material por crianças que convivem com a AF ainda não foi possível em função das restrições impostas pela pandemia de COVID-19. Reconhecendo a importância dessa etapa, um novo projeto de pesquisa está sendo elaborado com o objetivo de avaliar o quanto o material é informativo e contribui para a produção de mudança no nível de compreensão da criança após a contação da história.

Para a execução do projeto serão utilizadas, como recursos complementares, "hemácias" de crochê, para facilitar a compreensão da morfologia peculiar dos glóbulos vermelhos na AF (Figura 3).

Figura 3. Kit completo para a contação de história com crianças com doença falciforme.

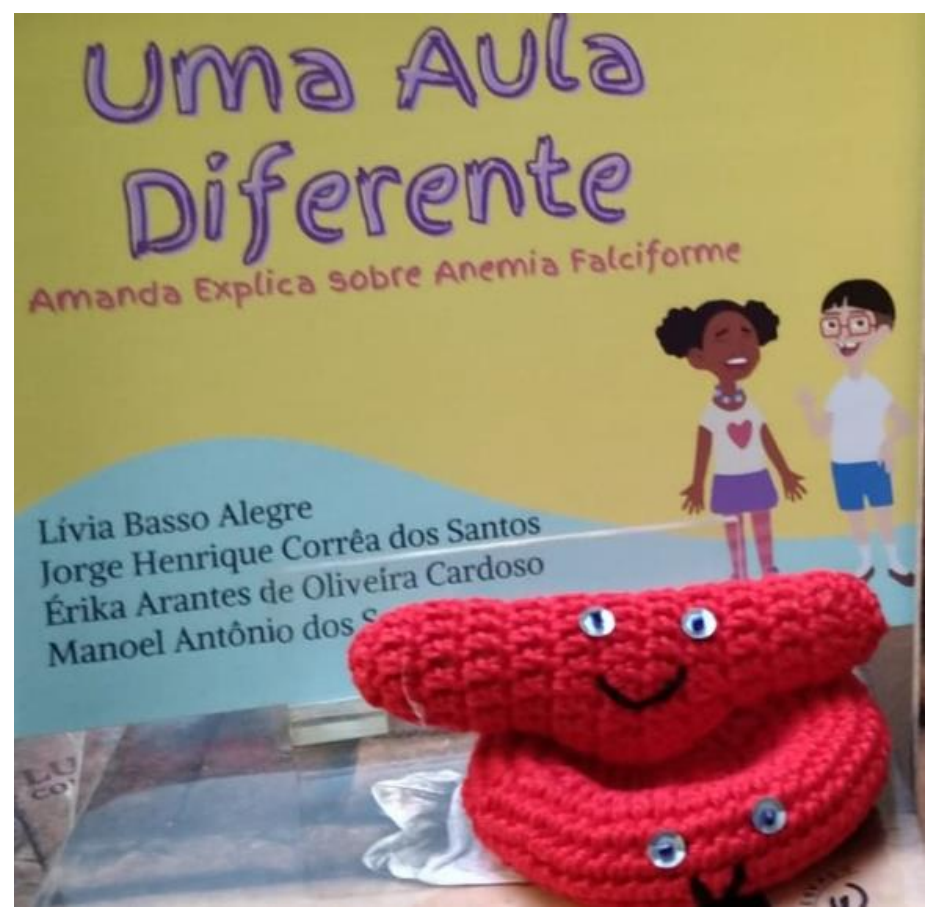

Fonte: Autores. 


\section{Considerações Finais}

A AF impacta a qualidade de vida dos pacientes, em especial das crianças, que precisam se adaptar às limitações da doença e à necessidade de retornos ambulatoriais frequentes, conciliando-as às exigências de seu processo de desenvolvimento (Lotério et al., 2022). Este estudo alcançou seu objetivo de descrever as etapas de elaboração de um livro educativo com o propósito de auxiliar a criança com $\mathrm{AF}$ a compreender o que se passa consigo.

A AF e seu tratamento têm repercussões especialmente na vida escolar das crianças e, considerando essa realidade, a história desenvolvida no livro se passa no cenário de uma escola (Custódio et al., 2018). A revisão da literatura orientou a escolha dos tópicos abordados no enredo: Necessidade de faltas na escola, Crises de dor, Restrições de atividades físicas escolares, Definições da doença, Sintomas e tratamento. Esses itens aparecem no diálogo dos dois personagens - Amanda e Gabriel. Para manter o tom coloquial, a conversa é desenvolvida em situações cotidianas e traz à baila a curiosidade e os conhecimentos das crianças, buscando ampliar sua compreensão. Para tanto, foram formuladas questões disparadoras, tais como: "Que doença é essa da Amanda?" "Em que parte do corpo ela fica?" "O que são essas crises de dores?" "Como você acha que essa doença funciona?" Ao final do livro foram adicionadas dicas para pais e professores, visando a facilitar a inserção do paciente na rotina escolar, além de orientações específicas aos cuidadores e uma explicação mais aprofundada da doença para pacientes mais adolescentes e adultos que possam eventualmente ter contato com o material.

O material produzido foi editado em formato de livro, o que possibilita que seja utilizado em diversos contextos: na escola, na família, nos serviços de saúde, entre outros, podendo servir como recurso intermediário facilitador da expressão emocional das crianças com AF, que facilmente se identificam com as vivências da personagem Amanda.

As avaliações dos leitores (crianças, pacientes adultos, familiares e profissionais) foram positivas, reforçando a adequação do material e a importância desse tipo de produção no cenário da promoção da saúde. Uma limitação encontrada foi a impossibilidade de aferição do material com as crianças com AF, sendo este o objetivo do próximo projeto a ser desenvolvido pelo Laboratório.

Espera-se que este estudo, para além do material produzido, possa também servir de inspiração e guia para a elaboração de outros materiais didáticos, cartilhas e manuais com finalidade educativa para serem utilizados no contexto da atenção à saúde, considerando as lacunas e necessidades de materiais bem elaborados do ponto de vista didático e do rigor científico, inclusive aqueles voltados para a capacitação de profissionais da saúde (Escher, 2005). O desconhecimento sobre a AF ainda é considerável, o que prejudica a assistência a essa população (Lima et al., 2021). Um dos desafios é sensibilizar e capacitar os profissionais para acolherem as necessidades de esclarecimento e educação dos pacientes e suas famílias.

Uma sugestão para futuros estudos é comparar a receptividade do livro por crianças de diferentes centros de tratamento do Brasil, com avaliação do grau de conhecimento sobre a doença antes e após o contato com o material, podendo também incentivar a realização de rodas de conversas sobre o conteúdo abordado.

\section{Agradecimentos}

Os autores agradecem o apoio financeiro do Programa Unificado de Bolsas da Universidade de São Paulo (PUBUSP).

\section{Referências}

Cançado, R. D., Lobo, C., Angulo, I., Araújo, P. I. C., \& Jesus, J. A. (2009). Protocolo clínico e diretrizes terapêuticas para uso de hidroxiureia na anemia falciforme. Revista Brasileira de Hematologia e Hemoterapia, 31(5), 361-6.

Brito, N., Lima, T. M., Dias, T. L., \& Enumo, S. R. F. (2017). A doença crônica no contexto escolar: os saberes de alunos com anemia falciforme. Revista de Educação Pública, 26(62-2), 675-93. https://doi.org/10.29286/rep.v26i62/2.5507 
Custódio, L., Gomes, I., \& Leitão, I. (2018). Limitações impostas à escolarização das crianças e adolescentes com doença falciforme. Série-Campos, 23(49), 249-266. http://dx.doi.org/10.20435/serie-estudos.v23i49.1128

Echer, I. C. (2005). Elaboração de manuais de orientação para o cuidado em saúde. Revista Latino-Americana de Enfermagem, 13(5), 754-7. https://doi.org/10.1590/S0104-11692005000500022

Enumo, S. R. F., Weide, J. N., Vicentini, E. C. C., Araujo, M. F. \& Machado, W. L. (2020). Enfrentando o estresse em tempos de pandemia: proposição de uma cartilha. Estudos de Psicologia (Campinas), 37, e200065. https://doi.org/10.1590/1982-0275202037e200065

Ezenwosu, O. U., Chukwu, B. F., Ezenwosu, I. L., Uwaezuoke, N. A., Eke, C. B., Udorah, M. I., \& Emodi, I. J. (2021). Clinical depression in children and adolescents with sickle cell anaemia: influencing factors in a resource-limited setting. BMC Pediatrics, 21, 533. https://doi.org/10.1186/s12887-021-03015- 1

Felix, A. A., Souza, H. M., \& Ribeiro, S. B. F. (2010). Aspectos epidemiológicos e sociais da doença falciforme. Revista Brasileira de Hematologia e Hemoterapia, 32(3), 203-8.

Freire, A. K. S., Belmont, T. F. M., Ó, K. P., Silva, A. S., Farias, I. C. C., Carvalho, M. F. A. A., Santiago, E. J. P., \& Cavalcanti, M. S. M. (2020). Assistência de enfermagem no manejo da dor em crianças com anemia falciforme: uma revisão integrativa. Research, Society and Development, 9(5), e182953353. https://doi.org/10.33448/rsd-v9i5.3353

Hoppe, C. C., \& Walters, M. C. (2001). Bone marrow transplantation in sickle cell anemia. Current Opinion in Oncology, 13(2), 85-90.

Kanter, J., \& Kruse-Jarres, R. (2013). Management of sickle cell disease from childhood through adulthood. Blood Reviews, 27, 279-87.

Lima, D. S., Figueiredo, S. V., Silva, A. C. A., Rodrigues, M. E. N. G., Vasconcelos, S. S., Menezes, C. P. S. R., Custodio, L. L., Lima, L. A., Silva, D. P. B., Costa, D. C. C. O., Santos, M. P., \& Gomes, I. L. V. (2021). Desafios enfrentados pelas pessoas com doença falciforme nas situações de crise: entraves nos serviços de emergência. Research, Society and Development, 10(5), e45410515078. https://doi.org/10.33448/rsd-v10i5.15078

Lotério, L. S., Oliveira-Cardoso, E. A., Simões, B. P., Oliveira, M. C., Garcia, J. T., Guimarães, A. L. C., Pereira, K. C., Costa, T. C. M., Cunha R. L. G., \& Santos, M. A. (2022). Quality of life of sickle cell disease patients after hematopoietic stem cell transplantation: a longitudinal study. Trends in Psychology, 28(1). https://doi.org/10.1007/s43076-021-00132-9

Nascimento, C. C. L., Silva, B. V. C., Oliveira, J. G. C., Nascimento, M. F. S., \& Ferreira, V. S. (2020). Tecnologia educativa para sala de imunização: confecção de bundle on conservação imunobiológica. Research, Society and Development, 9(7). http://dx.doi.org/10.33448/rsd-v9i7.4032

Nóbrega R. D., Collet N., Gomes I. P., Holanda E. R., \& Araújo Y. B. (2010). Criança em idade escolar hospitalizada: significado da condição crônica. Texto \& Contexto Enfermagem, 19(3), 425-33.

Palermo, T. M., Eccleston, C., Lewandowski, A. S., William, A. C. C., \& Morley, S. (2011). Randomized controlled trials of psychological therapies for management of chronic pain in children and adolescents: an updated meta-analytic review. Pain, 148(3), 387-97. http://dx.doi.org/10.1016/j.pain.2009.10.004

Rocha, P. K., Prado, M. L., \& Silva, D. M. G. V. (2012). Pesquisa Convergente Assistencial: uso na elaboração de modelos de cuidado de enfermagem. Revista Brasileira de Enfermagem, 65(6), 1019-102. http://dx.doi.org/10.1590/S0034-71672012000600019

Saraf, S. L., Oh, A. L., Patel, P. R., Jalundhwala, Y., Sweiss, K., Koshy, M., Campbell-Lee, S., Gowhari, M., Hassan, J., Peace, D., Quigley, J. G., Khan, I., Molokie, R. E., Hsu, L. L., Mahmud, N., Levinson, D. J., Pickard, A. S., Garcia, J. G., Gordeuk, V. R., \& Rondelli, D. (2016). Nonmyeloablative stem cell transplantation with alemtuzumab/low-dose irradiation to cure and improve the quality of life of adults with sickle cell disease. Biology of Blood and Marrow Transplantation, 22(3), 441-8. https://doi.org/10.1016/j.bbmt.2015.08.036

Silva, M. D. V. F. B., Santos, L. F., Falcão, G. C., Carmo Rodrigues, C. F., \& Evangelista, D. R. (2020). Processo de construção de material educativo para as puérperas sobre cuidados com o recém-nascido. Research, Society and Development, 9(11), e1879119747. http://dx.doi.org/10.33448/rsd-v9i11.9747

Tates, K., \& Meeuweesen, L. (2001). Doctor-parent-child communication: a (re)view of the literature. Social Science and Medicine, 52(6), 839-51.

Zago, M. A., \& Pinto A. C. S. (2007). Fisiopatologia das doenças falciformes: da mutação genética à insuficiência de múltiplos órgãos. Revista Brasileira de Hematologia e Hemoterapia, 29(3), 207-14. 